\title{
PENGARUH PENGEMASAN DAN WAKTU PENYIMPANAN BAHAN STEK MERANTI MERAH TERHADAP PERSENTASE BERAKAR STEK DI RUMAH KACA
}

(Effect of packging and storage time material cuttings of red mernti to rooted percentage

in greenhouse)

\author{
$\mathrm{Oleh} / \mathrm{By}$ : \\ R. Mulyana Omon dan/and Burhanuddin Adman \\ Balai Penelitian Teknologi Perbenihan Samboja
}

\begin{abstract}
The effect of packing and storage duration to rooted percentage of two red meranti (Shorea leprosula and Shorea parvifolia) cuttings was conducted in greeenhouse of Seed Tehnology Research Institute Samboja, East Kalimantan. The objective of this study to findout the effect of packing and storage duration to rooted cutting materials of two red meranti after three months obeservations. Cutting materials was taken from wilding in concession holder PT. IKANI, Bulungan East Kalimantan. Treatments consisted of two species, two packed and four storage duration. Factorial completely randomized design with three replications was used for this study. Each treatment consisted of 15 cuttings for $\mathrm{S}$. leprosula and 25 cuttings for $\mathrm{S}$. parvifolia. The total number of cuttings observed were 960. The resuts showed that treatments of species and storage duration bring effect to survival rate, number of roots and length of roots. Only storage duration treatment had carried effect to rooted percentage. The treatment of $\mathrm{S}$. leprosula cuttings was higher than $\mathrm{S}$. parvifolia to survival rate, number of roots and length of roots i.e: $34.27 \%, 2.0$ and $4.4 \mathrm{~cm}$ respectively. While treatment of three days was higher than other storage duration to survival rate, rooted percentage number of roots and length of roots i.e: $58.0 \%, 47.57 \%, 5.2 \mathrm{~cm}$ and 2 respectively. Interaction between $\mathrm{S}$. leprosula with coolbox was higher compered to other interaction to number of new leaf as much as one leaf. Therefore three days storage duration for a cutting material with cardboard box improved rooted percentage of two red meranti cuttings.
\end{abstract}

Key Words : Packaging, storage, cutting, red meranti.

\begin{abstract}
ABSTRAK
Penelitian pengaruh pengemasan dan waktu penyimpan terhadap persentase stek 2 jenis meranti merah (Shorea leprosula Miq. dan Shorea pervifolia) telah dilakukan di greenhouse Balai Teknologi Perbenihan, Samboja Kalimantan Timur. Bahan stek dimbil dari permudaan alam di IUPHHK PT. IKANI, Bulungan Kalimantan Timur.Tujuan dari penelitian ini untuk mengetahui informasi pengaruh pengemasan dan waktu penyimpanan terhadap persentase berakar stek 2 jenis meranti merah selama tiga bulan pengamatan. Perlakuan percobaan terdiri dari dua jenis, dua kemasan dan empat waktu penyimpan bahan stek. Rancangan percobaan yang digunakan adalah faktorial dengan pola acak lengkap dengan ulangan sebanyak tiga kali. Setiap perlakuan terdiri dari 15 stek untuk S. leprosula dan 25 stek untuk $S$. parvifolia. Jumlah stek yang diamati sebanyak 960 stek. Hasil penelitian menunjukkan bahwa jenis dan waktu penyimpanan memberikan pengaruh yang nyata terhadap persen hidup, jumlah akar dan panjang akar. Hanya perlakuan waktu penyimpanan berpengaruh nyata terhadap
\end{abstract}


persen berakar stek 2 jenis meranti merah. Perlakuan stek $S$. leprosula lebih baik dibandingkan dengan stek $S$. pervifolia terhadap persen hidup, persen berakar, jumlah akar dan panjang akar setelah tiga bulan pengamatan, yaitu masing-masing sebesar $34,27 \%, 2,0$ dan $4,4 \mathrm{~cm}$. Sedangkan perlakuan waktu penyimpanan tiga selama tiga hari lebih baik dibandingkan waktu penyimpanan lainnya terhadap persen hidup, persen berakar, jumlah akar dan panjang akar, yaitu masing-masing sebesar $58,0 \%$, $48 \%, 5,2 \mathrm{~cm}$ dan 2 daun. Interaksi antara jenis stek $S$. leprosula dengan penyimpanan di coolbox lebih baik dibandingkan dengan interaksi lainnya terhadap jumlah daun baru, yaitu sebesar dua daun. Dengan demikian waktu penyimpanan tiga hari masih dapat meningkatkan terhadap persen berakar dua bahan jenis meranti merah.

\section{Kata Kunci : Pengemasan, waktu penyimpana, stek, meranti merah.}

\section{PENDAHULUAN}

Dipterocarpaceae merupakan salah satu famili mempunyai banyak jenis dan kayunya bernilai ekonomi tinggi. Bahkan beberapa jenis mempunyai pertumbuhan yang cukup cepat seperti Shorea leprosula, S. parvifolia, S. johorensis, S. smithiana dan S. platyclados. Pada umur 4,5 tahun rata-rata riap diameter dapat mencapai 1,8 - 1,9 cm/th di kawasan Hak Pengusahaan Hutan Sari Bumi Kusuma, Kalimantan Tengah (Suparna dan Purnomo, 2004). Oleh karena itu jenis tersebut diprioritaskan untuk ditanam dalam program SILIN (Silvikultur Intensif) dengan sistem Tebang Pilih Tanam Indonesia Intensif (TPTII). Untuk menunjang program tersebut diperlukan bibit dalam jumlah yang cukup banyak dengan kualitas yang baik.

Sejak tahun 2005 telah ditunjuk enam pemegang Izin Usaha Pemanfaatan Hasil Hutan Kayu (IUPHHK) pada hutan alam sebagai model untuk kegiatan program Silin dengan Sistem TPTII melalui Surat Keputusan Direktorat Jenderal Bina Produksi Kehutanan (BPK), Departemen Kehutanan, Nomor: SK.221-BPH/VI-BPHA/2005. Bahkan pada saat ini yang telah mengikuti program Silin sebanyak 25 IUPHHK.

Untuk menunjang keberhasilan kegiatan program Silin diperlukan ketersediaan bibit yang berkualitas secara berkesinambungan. Upaya untuk pengadaan bibit jenis Dipterocarpaceae secara generatif yang berkesinambungan masih mengalami kendala. Kendala tersebut antara lain periodisitas pembungaan yang tidak teratur (Ashton, 1988). Bahkan Yasman dan Smits (1988) melaporkan bahwa jenis Dipterocarpaceae masa musim berbuah massal sekali dalam 4 sampai 13 tahun dengan waktu dorman benih yang sangat singkat hanya beberapa minggu saja (benih recalcitrant). Salah satu alternatif pemecahannya adalah perbanyakan tanaman melalui pembiakan vegetatif dengan stek pucuk. Keuntungan pembiakan vegetatif dengan stek pucuk adalah perbanyakan jenis dapat dihasilkan secara massal, homogen dan dapat digunakan untuk menganalisa kualitas tempat tumbuh (Yasman dan Smits, 1988). Kebutuhan bibit untuk penanaman jenis fast growing meranti sesuai 
dengan penyebarannya tidak menjadi masalah, walaupun belum musim berbuah massal masih dapat dilakukan pengadaan bibit dari cabutan. Akan tetapi untuk keperluan penanaman secara ex-situ akan kesulitan untuk memenuhi kebutuhan bibit tersebut, sehingga perlu dilakukan penelitian teknik pengemasan dan penyimpanan bahan stek pucuk, khusus meranti yang pertumbuhannya cepat.

Penelitian ini bertujuan untuk mempelajari lamanya penyimpanan bahan stek dengan berbagai pengemasan terhadap persentase berakar dua jenis meranti merah ( $S$. leprosula dan S. parvifolia). Diharapkan hasil dari penelitian ini dapat memberikan informasi penyedian bibit untuk penanaman meranti ex-situ.

\section{METODOLOGI}

\section{A. Lokasi dan Waktu}

Lokasi pengambilan bahan stek dilakukan di kawasan hutan IUPHHK PT. IKANI, Kalimantan Timur. Secara administratif pemerintahan termasuk Desa Long Beluah, Kecamatan Tanjung Palas Barat, Kabupaten Bulungan, Propinsi Kalimatan Timur.

Waktu penelitian dilakukan pada bulan Agustus dengan pengambilan bahan stek dari permudaan alam. Selanjutnya stek dikemas dalam coolbox dan stek dimasukkan kedalam kantong plastik dan dikemas dalam kardus. Untuk pengamatan proses perakaran dilakukan dari pertengahan bulan Agustus sampai dengan pertengahan Nopember 2007 di rumah kaca, Balai Penelitian Teknologi Perbenihan Samboja.

\section{B. Bahan Peneltian}

Bahan yang digunakan dalam penelitian ini adalah stek dari jenis meranti merah, yaitu $S$. leprosula dan S. parvifolia yang diambil dari permudaan alam di areal IUPHHK PT IKANI. Alat yang digunakan dalam penelitian ini adalah gunting stek coolbox berukuran $(50 \mathrm{~cm} \times 30 \mathrm{~cm} \times 37 \mathrm{~cm})$, kantong plastik berwarna bening berukuran $15 \mathrm{~cm} \times 20 \mathrm{~cm}$ dan kardus berukuran $(35 \mathrm{~cm} \times 25 \mathrm{~cm} \times 15$ $\mathrm{cm}$ ). Selanjutnya stek disimpan dalam kemasan coolbox dan kardus (yang berisi stek dalam kantong plastik). Tranportasi dari lokasi pengambilan stek sampai dengan proses perakaran di rumah kaca Balai Penelitian Teknologi Perbenihan Samboja menggunakan jalan darat (kendaraan roda empat), sungai (dengan speedboat) dan udara (pesawat). Proses perakaran ke dua stek dilakukan di bak stek dengan media padat (arang sekam padi).

\section{Rancangan Percobaan}

Penelitian ini menggunakan rancangan faktorial $2 \times 2 \times 4$ dalam pola acak lengkap yang diulang sebanyak 3 kali. Faktor-faktor tersebut terdiri dari:

Faktor A, yang terdiri dari dua jenis :

$\mathrm{A}_{1}=$ stek $S$. leprosula 
$\mathrm{A}_{2}=$ stek $S$. parvifolia

Faktor B, terdiri dari dua kemasan (penyimpan bahan stek)

$\mathrm{B}_{1}=$ coolbox

$\mathrm{B}_{2}=$ kardus

Faktor $\mathrm{C}$ adalah waktu penyimpanan terdiri

$\mathrm{C}_{1}=3$ hari (waktu angkutan bibit),

$\mathrm{C}_{2}=6$ hari,

$\mathrm{C}_{3}=9$ hari

$\mathrm{C}_{4}=12$ hari.

Setiap ulangan terdiri dari 15 stek untuk jenis $S$. leprosula dan 25 stek untuk $S$. parvifolia yang diulang sebanyak tiga kali. Jumlah stek yang diamati untuk $S$. leprosula sebanyak 360 stek dan $S$. parvifolia sebanyak 600 stek. Perbedaan jumlah stek yang diamati ini dikarenakan keterbatasan bahan stek di lapangan.

Sebelum dikemas bahan stek diikat sesuai jumlah satuan pada tiap-tiap ulangan, kemudian dibasahi dengan air, selanjutnya disusun secara terbalik pada masing-masing kemasan (Gambar 1). Untuk pengemasan dalam kardus, stek terlebih dahulu dimasukkan dalam kantong plastik yang berisi air sebanyak $10 \mathrm{ml}$ dan diikat rapat. Untuk stek yang dikemas pada coolbox diberi air sebanyak 200 ml. Pemberian air pada kedua kemasan tersebut adalah untuk menjaga kelembaban agar bahan stek selalu segar.
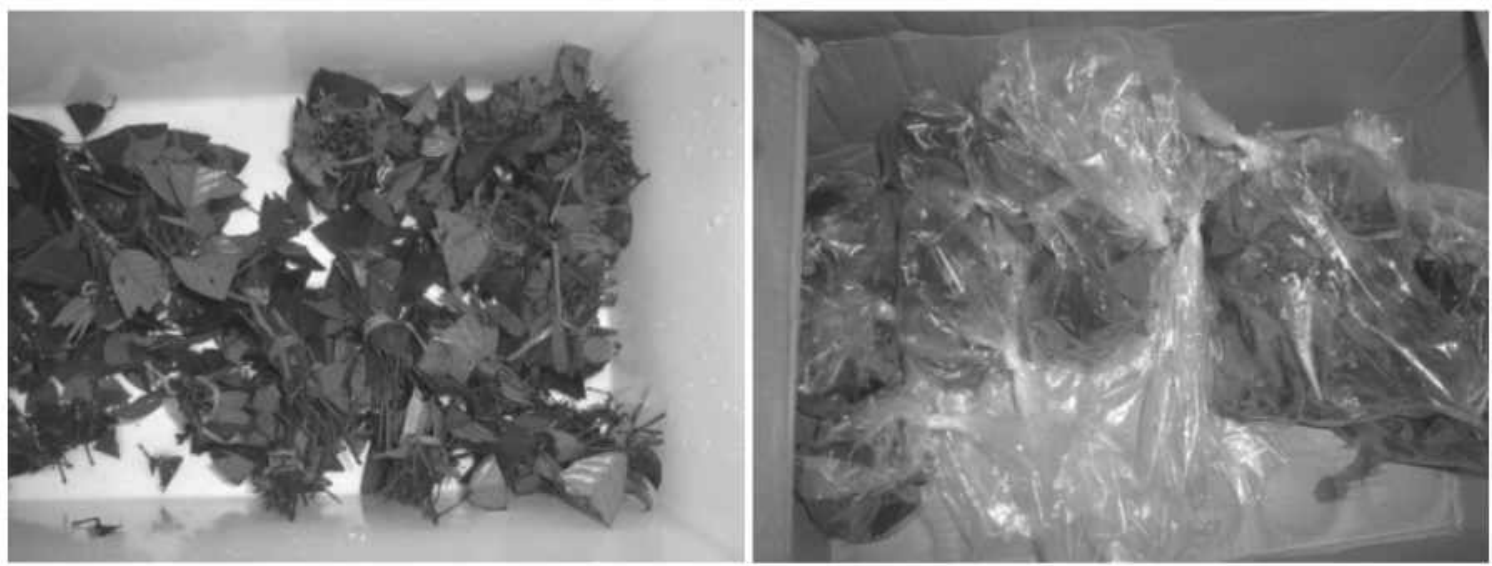

Gambar (Figure) 1. Bahan stek jenis Shorea leprosula dan S. parvifolia dikemas di coolbox dan kardus (Cutting materials of Shorea leprosula and S. parvifolia was packaged in coolbox and cardboard box).

Waktu mulai pengambilan stek, pengemasan, pengangkutan sampai tiba di lokasi penelitian dan ditanam pada bak stek dihitung sebagai $\mathrm{C}_{1}$. Selanjutnya bahan stek yang disimpan berikutnya dengan selang waktu tiga hari menjadi $\mathrm{C}_{2}, \mathrm{C}_{3}$ dan $\mathrm{C}_{4}$. 


\section{Pengukuran dan Analisis Data}

Parameter yang diukur dalam penelitian ini adalah persen hidup stek, persen berakar, jumlah akar, panjang akar dan jumlah daun baru. Pengamatan proses perakaran dilakukan setelah tiga bulan ditanam pada media arang sekam padi.

Persen hidup diperoleh dari persentase stek yang ditanam selama tiga bulan, walaupun belum berakar. Persen berakar diperoleh dari persentase stek yang telah berakar pada akhir pengamatan selama tiga bulan. Jumlah akar dihitung dari jumlah akar yang keluar dari batang stek. Panjang akar diukur dari tumbuhnya akar hingga ujung akar. Jumlah daun baru dihitung dari daun yang tumbuh.

Analisis data yang digunakan adalah analisis keragaman dengan uji F. Apabila terdapat perbedaan yang nyata antara perlakuan maupun interaksi ketiga faktor dilakukan uji lanjutan dengan uji beda nyata Tukey (Haeruman, 1975).

\section{HASIL DAN PEMBAHASAN}

\section{A. Persen hidup}

Berdasarkan analisis keragaman perlakuan jenis, kemasan dan waktu penyimpanan berpengaruh nyata terhadap persen hidup stek $S$. leprosula dan $S$. parvifolia. Untuk semua interaksi antara perlakuan tidak berpengaruh nyata terhadap persen hidup ke dua jenis stek.

Untuk mengetahui pengaruh perlakuan tersebut di atas perlu dilakukan uji lanjutan dengan uji beda nyata Tukey. Dari hasil uji beda diperoleh nilai $\mathrm{W}_{(0,05)}$ masing-masing sebesar 2,8 dan 3,7.
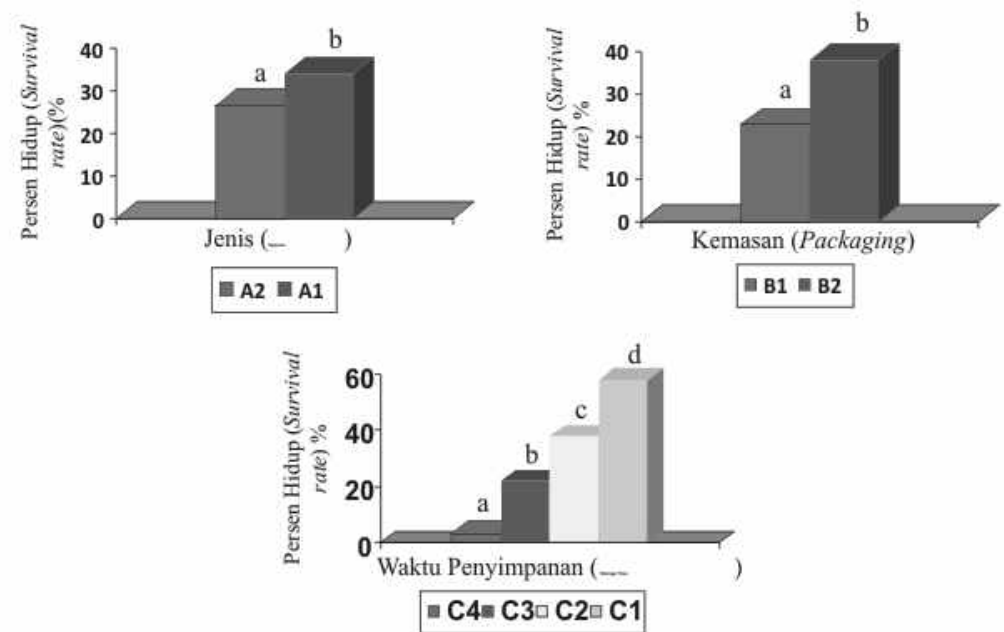

Gambar (Figure) 2. Hasil uji beda nyata Tukey perlakuan jenis, kemasan dan waktu penyimpanan terhadap persen hidup stek S. leprosula dan S. parvifolia (Result of significant difference Tukey test of species, packaging and storage time to survival rate of $\mathrm{S}$. leprosula and Shorea parvifolia cuttings).

Keterangan (Remarks): $\mathrm{A} 1=$ S. leprosula $\mathrm{A} 2=$ S. parvifolia $; \mathrm{B} 1=\mathrm{Cool}$ box, $\mathrm{B} 2=$ Kardus $($ cardboard box $) ; \mathrm{C} 1=$ tiga hari (three day), $\mathrm{C} 2=$ enam hari (six days), $\mathrm{C} 3=$ sembilan hari (nine days), $\mathrm{C} 4=12$ hari (tweleve days). 
Berdasarkan hasil uji beda nyata perlakuan pengemasan stek dengan kardus memperlihatkan lebih tinggi dibandingkan dengan kemasan coolbox terhadap persen hidup stek, yaitu masing-masing sebesar $38,1 \%$ dan $22,8 \%$. Perlakuan jenis $S$. leprosula lebih tingggi dibandingkan dengan $S$. parvifolia, yaitu masing-masing sebesar $34,2 \%$ dan $26,7 \%$. Untuk perlakuan penyimpanan stek yaitu $\mathrm{C}_{1}$ (waktu stek yang disimpan selama perjalanan), yaitu selama tiga hari lebih tinggi dibandingkan waktu penyimpanan lainnya yaitu masing-masing sebesar 58\%, 38\%, 22,1\% dan 3,7\% (Gambar 2).

\section{B. Persentase berakar stek}

Berdasarkan analisis keragaman hanya perlakuan waktu penyimpanan yang berpengaruh nyata terhadap persen berakar stek $S$. leprosula dan S. parvifolia. Untuk perlakuan jenis dan pengemasan serta interaksi antara perlakuan tidak berpengaruh nyata terhadap persen berakar ke dua jenis stek. Dari hasil uji beda nyata Tukey terhadap waktu penyimpanan diperoleh nilai $\mathrm{W}_{(0,05)}$ sebesar 3,8 . Gambar 3 memperlihatkan bahwa waktu penyimpanan selama tiga hari $\left(\mathrm{C}_{1}\right)$ persentase berakar ke dua jenis stek lebih tinggi dibandingkan dengan waktu penyimpanan lainnya yaitu sebesar $48 \%$.

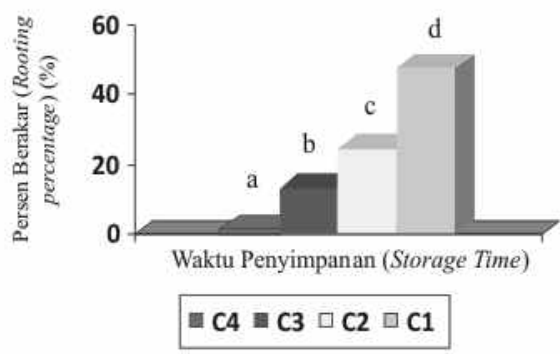

Gambar (Figure) 3. Hasil uji beda nyata Tukey perlakuan waktu penyimpanan terhadap persen berakar stek S. leprosula dan S. parvifolia. (Result of significant difference Tukey test of storage time to rooting percentage of $\mathrm{S}$. leprosula and $\mathrm{S}$. parvifolia cuttings)

Keterangan (Remarks): $\mathrm{C} 1=$ tiga hari (three day), $\mathrm{C} 2=$ enam hari (six days), $\mathrm{C} 3=$ sembilan hari (nine days), $\mathrm{C} 4=$ duabelas hari (tweleve days).

\section{Jumlah akar}

Hasil analisis keragaman perlakuan jenis dan waktu penyimpanan berpengaruh nyata terhadap jumlah akar stek $S$. leprosula dan S. parvifolia. Perlakuan pengemasan dan interaksi antara perlakuan tidak berpengaruh nyata terhadap jumlah akar ke dua jenis stek.

Dari hasil uji beda nyata Tukey terhadap jumlah akar diperoleh nilai $\mathrm{W}_{(0,05)}$ masing-masing sebesar 0,2 dan 0,2. Gambar 4 yang menunjukkan bahwa jumlah akar stek jenis $S$. leprosula lebih banyak dibandingkan dengan jenis $S$. parvifolia, yaitu sebanyak 1,6 buah. Begitu pula dengan waktu penyimanan selama tiga hari $\left(\mathrm{C}_{1}\right)$ jumlah akar lebih banyak dibandingkan dengan waktu penyimpan lainnya, yaitu sebanyak dua buah. 

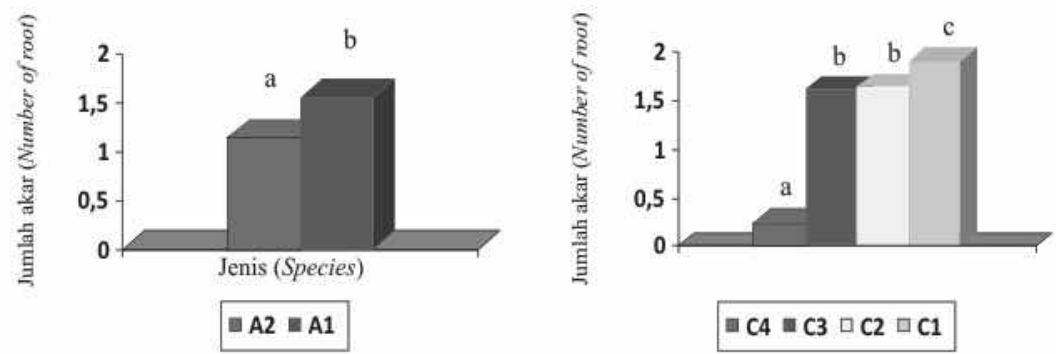

Gambar (Figure) 4. Hasil uji beda nyata Tukey perlakuan jenis dan waktu penyimpanan terhadap jumlah akar stek S. leprosula dan S. parvifolia (Result of significant difference Tukey test of species and storage time to number of root of $\mathrm{S}$. leprosula and $\mathrm{S}$. parvifolia cuttings)

Keterangan (Remarks) : $\mathrm{A} 1=\mathrm{S}$. leprosula $\mathrm{A} 2=\mathrm{S}$. parvifolia $; \mathrm{C} 1=$ tiga hari (three day), $\mathrm{C} 2=$ enam hari (six days), $\mathrm{C} 3=$ sembilan hari (nine days), $\mathrm{C} 4=12$ hari (tweleve days).

\section{Panjang akar}

Berdasarkan analisis keragaman perlakuan jenis dan waktu penyimpanan berpengaruh nyata terhadap panjang akar stek $S$. leprosula dan $S$. parvifolia, sedangkan perlakuan pengemasan dan interaksi antara perlakuan tidak berpengaruh nyata terhadap panjang akar ke dua jenis stek.

Hasil uji beda nyata Tukey diperoleh nilai $\mathrm{W}_{(0,05)}$ masing-masing sebesar 0,5 dan 0,6 . Hasil uji beda nyata memperlihatkan jenis stek $S$. leprosula akarnya lebih panjang dibandingkan dengan $S$. parvifolia, yaitu sepanjang $4,4 \mathrm{~cm}$. Hal yang sama dengan persentase hidup, persentase berakar dan jumlah akar, waktu penyimpanan selama tiga hari $\left(\mathrm{C}_{1}\right)$ memperlihatkan akar lebih panjang dibandingkan dengan waktu penyimpanan lainnya.yaitu sepanjang $5,2 \mathrm{~cm}$.
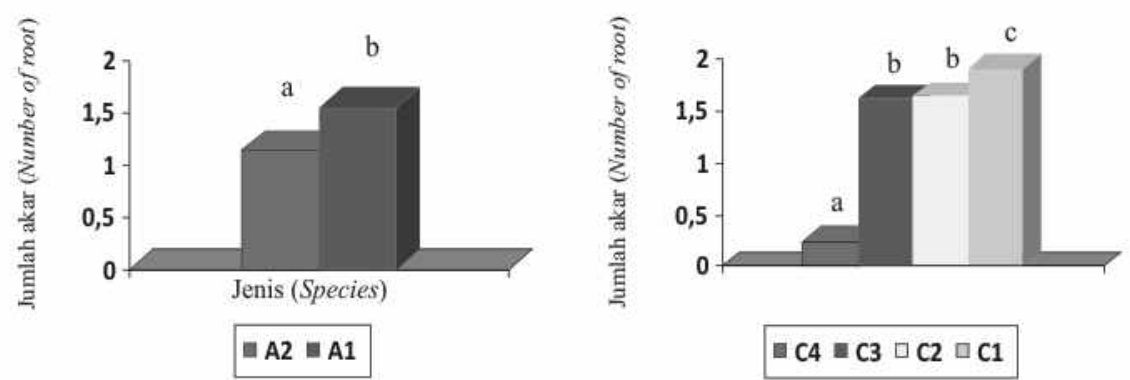

Gambar (Figure) 5. Hasil uji beda nyata Tukey perlakuan jenis dan waktu penyimpanan terhadap jumlah akar stek S. leprosula dan S. parvifolia (Result of significant difference Tukey test of species and storage time to length of root of $\mathrm{S}$. leprosula and $\mathrm{S}$. parvifolia cuttings)

Keterangan (Remarks): $\mathrm{A} 1=S$. leprosula $\mathrm{A} 2=$ S. parvifolia $; \mathrm{C} 1=$ tiga hari $($ three day), $\mathrm{C} 2=$ enam hari (six days), $\mathrm{C} 3=$ sembilan hari (nine days), $\mathrm{C} 4=12$ hari (tweleve days).

\section{E. Jumlah daun baru}

Hasil analisis keragaman menunjukkan bahwa interaksi perlakuan antara jenis dan pengemasan berpengaruh nyata terhadap jumlah daun baru kedua jenis stek. Perlakuan jenis, pengemasan dan waktu penyimpanan tidak berpengaruh nyata terhadap jumlah daun baru ke dua jenis stek. 
Hasil uji beda nyata Tukey terhadap jumlah daun baru diperoleh nilai $\mathrm{W}_{(0,05)}$ masing-masing sebesar 0,5 dan 0,6. Gambar 6 menunjukan bahwa jenis sincerelytek $S$. leprosula dengan coolbox lebih baik dibandingkan dengan interaksi lainnya terhadap jumlah daun baru, yaitu sebanyak 0,5 helai.

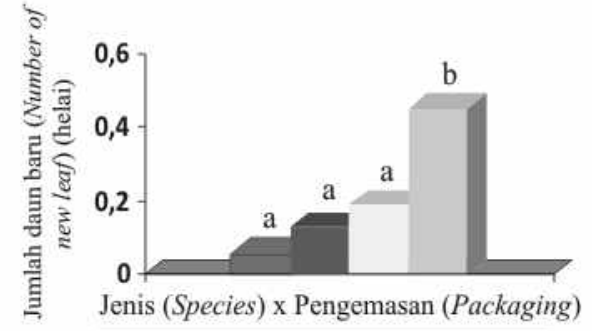

a $\mathrm{A} \times \mathrm{B} 1=\mathrm{A} 1 \times \mathrm{B} 2 \square \mathrm{A} 2 \times \mathrm{B} 2 \square \mathrm{A} 1 \times \mathrm{B} 1$

Gambar (Figure) 6. Hasil uji beda nyata Tukey interaksi perlakuan jenis dan pengemasan terhadap jumlah daun baru stek $S$. leprosula dan S. parvifolia (Result of significant difference Tukey test of interactions of species and packaging to number of new leaf of $\mathrm{S}$. leprosula and S. parvifolia cuttings)

Keterangan (Remarks): $\mathrm{A} 1=$ S. leprosula $\mathrm{A} 2=$ S. parvifolia $; \mathrm{B} 1=$ Cool box, $\mathrm{B} 2=$ Kardus $($ cardboard box $)$

Berdasarkan Gambar 2 dan Gambar 3 menunjukkan persentase hidup dan persentase berakar ke dua stek meranti merah masih rendah, yaitu $61 \%$ dan $44 \%$. Rendahnya persentase hidup dan persentase berakar kedua stek, akibat dari suhu yang tinggi didalam coolbox dan kardus pada waktu pengangkutan dari lokasi bahan stek diambil ke tempat proses perakaran. Terlihat bahwa daun pada bahan stek menjadi terbakar, kemudian sebagian daunnya jatuh, tetapi batang steknya masih hijau. Untuk persentase berakar stek jenis $S$. leprosula lebih tinggi dibandingkan dengan $S$. parfivolia. Hal ini dikarenakan untuk jenis stek $S$. leprosula lebih muda berakar, baik pada media padat maupun cair (Priadjati dan Tolkamp, 2002). Omon (2002) melaporkan bahwa stek S. leprosula setelah dua minggu ditanam sudah mulai berakar, akan tetapi setelah pengambilan bahan stek langsung ditanam dengan menggunakan hormon Rootone-F perangsang akar. Walaupun demikian bahan stek jenis ini setelah disimpan selama tiga hari tanpa pemberian hormon perangsang akar masih lebih tinggi yaitu sebesar 48\% (Gambar 3). Sakai dan Subiakto (2007) menyatakan waktu pembentukan akar stek bervariasi tergantung jenis tanamannya.

Dari hasil uji beda (Gambar 2) menunjukkan bahwa persentase hidup dan persentase berakar stek yang dikemas di dalam kardus lebih baik dibandingkan di dalam coolbox, walaupun untuk persen berakar secara statistik tidak berbeda nyata. Hartmann et al. (1990) menyatakan keberhasilan penyimpanan stek yang belum berakar tergantung pada kondisi penyimpanan, yaitu dalam unit penyimpanan sebaiknya menjaga kelembaban mendekati $100 \%$.

Hasil uji beda nyata menunjukkan bahwa waktu penyimpanan selama tiga hari $\left(\mathrm{C}_{1}\right)$ telah memberikan perbedaan yang nyata terhadap persentase hidup, persentase berakar stek dan jumlah akar, yaitu masing-masing sebesar 58\%, 48\%, 5,2 cm dan 2 daun (Gambar 2, Gambar 3, Gambar 4 dan Gambar 5) dibandingkan dengan waktu penyimpanan lainnya. Hal tersebut ternyata memperlihatkan 
makin lama bahan stek disimpan cenderung menurunkan persen hidup, persen berakar dan jumlah akar. Menurunnya parameter tersebut seperti yang dikemukakan oleh Hartmann et al. (1990) bahwa jangka waktu pengiriman dapat mempengaruhi kualitas akibat penguapan yang berlebihan, kekurangan cahaya, kehilangan kelembaban, serangan patogen dan/atau pembentukan ethylene. Seperti pada jenis stek Croton (Codiaeum variegatum) masih memiliki kualitas baik ketika disimpan selama 5 sampai 10 hari pada suhu $10^{\circ}-30^{\circ} \mathrm{C}$ atau 15 hari pada $15^{\circ}-20^{\circ} \mathrm{C}$ (Wang 1987) dalam Hartmann et al. 1990).

Terjadinya interaksi antara jenis stek $S$. leprosula yang disimpan dalam coolbox lebih baik dibandingkan dengan interaksi lainnya terhadap pertumbuhan daun baru. Hal ini dikarenakan perkembangan akar yang baik akan memacu perkembangan tunas, karena mungkin dikarenakan adanya pembentukan sitokonin yang diperlukan untuk pembentukan tunas terjadi di titik tumbuh akar (Salisbury dan Ross, 1992). Dengan demikian untuk pengemasaan dengan kardus masih memberikan harapan yang cukup baik dibandingkan dengan coolbox, karena suhu didalam coolbox lambat menurun dibandingkan dengan kardus pada waktu pengangkutan. Selain itu waktu penyimpanan bahan selama tiga hari masih cukup baik untuk membentuk proses perakaran stek. Walaupun demikian akan terus diusahakan dengan berbagai kemasan bahan stek dan waktu penyimpanan yang optimal terhadap persentase perakaran dari bahan stek jenis-jenis meranti merah lainnya.

\section{KESIMPULAN DAN SARAN}

1. Jenis stek $S$. leprosula lebih baik dibandingkan dengan stek $S$. parvifolia terhadap persentase hidup, jumlah akar dan panjang akar yaitu masing-masing sebesar 34,27\%, 2,0 dan 4,4 cm.

2. Waktu penyimpanan bahan stek selama tiga hari lebih baik dibandingkan dengan waktu penyimpanan lainnya terhadap persentase hidup, persentase berakar, jumlah akar dan panjang akar masing-masing sebesar $58 \%, 48 \%, 5,2 \mathrm{~cm}$ dan 2 daun.

3. Lamanya penyimpanan bahan stek cenderung menurunkan persentase berakar kedua stek meranti merah, sedangkan pengemasan stek dengan kardus lebih baik dibandingkan dengan coolbox terhadap persen hidup yaitu sebesar $38,1 \%$.

\section{Saran-saran}

Perlu dicari bentuk pengemasan yang baik untuk bahan stek agar diperoleh persen berakar yang lebih tinggi dengan waktu penyimpanan stek lebih dari tiga hari. 


\section{DAFTAR PUSTAKA}

Ashton, P.M.S., Givinish, T.J., and Appanah, S. 1998. Staggered Flowering in Dipterocarpaceae: New insight into floral induction and the evolution of mast flowering in the seasonal tropic. American Naturalist 132: 44-60.

Direktorat Jendral Bina Produksi Kehutanan, 2005. Pedoman Tebang Pilih Tanam Indonesia Intensif/TPTII (Silvikultur Intensif). Direktorat Bina Pengembangan Hutan Alam, Direktorat Jenderal Bina Produksi Kehutanan, Departemaen Kehutanan.

Haeruman, H. 1975. Prosedur analisa rancangan percobaan. Bagian pertama. Bagian Perentjanaan Hutan. Departemen Mangemen Hutan, Fakultas Kehutanan, IPB, Bogor. 78 h.

Hartmann, H.T., D.E. Kester, F.T. Davies. 1990. Plant Propagation Principles and Practices. Fifth Edition. Prentice-Hall International Inc. Eaglewood Cliffs. New Jersey.

Moko, H. 2004. Teknik Perbanyakan Tanaman Hutan Secara Vegetatif. Informasi Teknis Vol. 2 No. 1 Juni 2004. Pusat Penelitian dan Pengembangan Bioteknologi dan Pemuliaan Tanaman Hutan. Yogyakarta.

Omon, R. M. 2002. Dipterocarpaceae: Shorea leprosula Miq., Cuttings, Mycorrhizae and Nutrients. Tropenbos Series No 7. The Tropenbos Foundation, Wageningen, the Netherlands. 144 pp

Pridjati, A. dan G.W. Tolkamp., 2002. Manual Persemaian Dipterocarpaceae. Badan Penelitian dan Pengembangan Kehutanan, Tropenbos International, SFMP (GTZ), APHI, IFSP (DANIDA). h. IV-1 -IV-7

Sakai, C., A. Subiakto. 2007. Pedoman Pembuatan Stek Jenis-jenis Dipterocarpaceae dengan KOFFCO System. Kerjasama antara: Badan Litbang Kehutanan, Komatsu dan JICA. Pusat Penelitian dan Pengembangan Hutan dan Konservasi Alam. Bogor.

Salisbury, F.B. and C.W. Ross. 1992. Plant Physiology. Fourth Edition. Wadsworth Publising Company. California.

Suparna, N dan Purnomo, 2004. Pengalaman Membangun Hutan Tanaman Meranti Di PT. Sari Bumi Kusuma Kalimantan Tengah. Makalah Disampaikan Pada Seminar Nasional Dalam Rangka 70 Tahun Prof. Dr. Ir. Soekotjo Dengan Tema Visi Silvikultur Indonesia Menyongsong Kehutanan 2045 Tanggal 4-5 Maret 2004, di Yogyakarta.

Yasman dan Smits, 1988. Metode Pembuatan stek Dipterocarpaceae. Edisi Khusus Balai Penelitian Kehutanan Samarinda, Samarinda. 